\title{
Paediatric focal intracranial suppuration: a UK single-centre experience
}

\author{
Theresa S. Cole • Julia E. Clark
}

Received: 20 November 2012 / Accepted: 23 November 2012 /Published online: 10 January 2013

(C) Springer-Verlag Berlin Heidelberg 2013

\section{Dear Editor:}

Prof Gelabert-Gonzalez et al. have raised some valid points. We agree that surgery should always be considered for brain abscesses.

However, it is widely accepted that, in some circumstances, medical treatment alone can be successful. These include children with a short duration of illness, with no signs of raised intracranial pressure, with either a solitary abscess less than 2 or $3 \mathrm{~cm}[1,2]$ and those with multiple small abscesses, especially where the causative agent has been identified [1].

Two children in our series did not have surgery due to the perceived risk outweighing the benefit: one was a 3-weekold baby with a small abscess in the internal capsule following pneumococcal meningitis and the other was a preterm infant with a large abscess following Enterbacter cloacae meningitis who was symptomatic since birth. For both these children, the pathogen was known and, therefore, diagnostic aspiration was unnecessary, and medical treatment was assessed as likely to succeed.

Regarding the duration of treatment, we recognise that children in our series received considerably longer courses of antibiotics than have been recommended in the recent literature. The centre involved has adopted a cautious approach to management of such significant

\section{T. S. Cole}

Institute of Cellular Medicine,

Newcastle University, Newcastle, UK

J. E. Clark

Royal Children's Hospital, Brisbane, Australia

\section{T. S. Cole $(\square)$}

Paediatric Immunology and Infectious Diseases Department, Old Children's Outpatients, Royal Victoria Infirmary,

Newcastle NE1 4LP, UK

e-mail: theresa.cole@ncl.ac.uk infections, which historically have significant mortality and still carry significant morbidity. This approach has involved careful monitoring of inflammatory markers, and neuroimaging and antibiotics were often been continued until these were normal. The difference between the duration of treatment for the group that did and did not undergo surgery reflects the fact that the majority of those that did not have surgery were deemed to be improving without the need for surgical intervention and, as such, required less treatment. Children with BA or SDE were jointly managed by the neurosurgeons and the paediatric infectious diseases team, and the duration of treatment was decided on an individual patient basis.

The hospital does have an empiric antibiotic policy, recommending which antibiotics to use but not the duration of treatment. This was referenced in the article but not explicitly described. One of the drivers for reviewing the management of these infections at our centre was precisely this question of the duration of treatment, in order to compare our prescribing with that in the literature. The results highlight the need for local and national paediatric guidelines.

There is no consensus on the best antibiotic management of brain abscesses in children, and our aim in publishing our experience was to aid in the discussions about how these infections should be managed in the future. We would welcome further discussion on this matter.

\section{References}

1. Sheehan JP, Jane JA Jr, Ray DK, Goodkin HP (2008) Brain abscess in children. Neurosurg Focus 24:1-5

2. Yogev R, Bar-Meir M (2004) Management of brain abscesses in children. Pediatr Infect Dis J 23:157-159 